\title{
La traducción como otro panorama para la pedagogía
}

\section{Translation as an Alternative Panorama for Pedagogy}

\author{
Juan Heiblum Amaya \\ Universidad Nacional Autónoma de México \\ Facultad de Filosofía y Letras \\ juanheiblum@hotmail.com \\ orcid.org/oooo-ooo3-1557-7649
}

Resumen: En el presente artículo hacemos una revisión del proyecto pedagógico de Paulo Freire, para poner en tela de juicio ciertos aspectos de su teoría, a saber: la figura del maestro presentada como justificación para intervenir en la vida de otro; su noción de progreso; la primacía de la lectoescritura por encima de otras formas de transmisión del saber. Ante la crítica al proyecto de Freire, proponemos el trabajo de traducción como alternativa al problema de la emancipación vernácula. Dentro del terreno de la ética heterónoma, fundada por Emmanuel Lévinas, podemos problematizar la lengua desde los siguientes aspectos: la oralidad y la escritura; la lengua como herencia; la traducción como resistencia. La presente crítica intenta proponer la traducción como otro panorama para la pedagogía.

Palabras clave: traducción, pedagogía, heteronomía, resistencia, alteridad

Abstract: In the present article we review the pedagogical project of Paulo Freire, to question certain aspects of his theory, namely: the figure of teacher presented as a justification for intervening in the others' life; his notion of progress; the primacy of literacy over other forms of knowledge transmission. Facing the critique to Freire's project we propose the task of translation as an alternative to the problem of vernacular emancipation. Within the field of heteronomous ethics, established by Emmanuel Levinas, we can problematize language from the following aspects: orality and writing; language as heritage; translation as resistance. This critique attempts to propose translation as another panorama for pedagogy.

Keywords: $\quad$ translation, pedagogy, heteronomy, resistance, alterity

Recibido: $\quad 25$ de mayo de 2019

Aceptado: $\quad 29$ de enero de 2020 
"Les anunciamos la civilización", dijo el extranjero Mahmud Darwish

La pedagogía es un saber que asume la responsabilidad de enseñarle a otro. Esta, más que presentarse como un ámbito homogéneo y bien determinado, se nos muestra como un espacio construido a partir de diversas experiencias. Grandes pensadores se han dedicado a repensar y criticar el camino que la pedagogía había tomado hasta sus tiempos. Paulo Freire es uno de estos pensadores. Encabezó una de las críticas más feroces al viejo régimen de la pedagogía, del que denunciaba alienación y enajenación de los alumnos, a los que se mantenía bajo el yugo opresor. El pedagogo brasileño se levanta en la segunda mitad del siglo xx para izar la bandera de una nueva pedagogía: la pedagogía del oprimido. ${ }^{1}$ El camino que la educación había tomado hasta ese punto se volcó hacia una propuesta por la presunta libertad y la justicia de aquellos que habían sido subyugados.

Así pues, la luz que brindó Freire a la pedagogía suele presentarse como un alivio a todos los sistemas más retrógrados de la educación. Sin embargo, la lectura que yo propongo pretende presentar esta propuesta pedagógica como un proyecto colonizador que, lejos de encaminarse hacia el fin que se proponía, resulta incluso contraproducente. A lo largo del artículo intentaré mostrar cómo este proyecto pedagógico se funda sobre la justificación de intervenir en la vida del otro, imponiendo una noción propia de justicia, negando la alteridad y promoviendo una idea de progreso que puede perjudicar a aquellos que originalmente se quería ayudar. No busco criticar los motivos de Freire, ni todas las campañas de alfabetización que hoy siguen su método. Mi crítica se dirige exclusivamente a la teoría que, finalmente, él identificaba como inseparable de su práctica.

En la Pedagogía del oprimido Freire hace un análisis de la opresión que parte de la lucha de clases marxista para construir un escenario que explique el proceso por el cual unos oprimen a otros. Mientras que muchos marxistas habían buscado en la lucha revolucionaria el camino a la liberación, Freire concibe la educación como el único lugar posible para lograr la verdadera libertad del oprimido. Mientras no haya una educación liberadora, podrán

1 Al hablar de pedagogía intentaremos hacerlo desde la noción freiriana de pedagogía del oprimido. Freire la distingue de la concepción bancaria. Como en el presente artículo intentamos dialogar con la propuesta de Freire, mas no con su crítica, nos referiremos meramente a la pedagogía del oprimido. 
cambiar los actores de la opresión, pero el sistema se conservará permanentemente. Únicamente con una pedagogía crítica podrá la humanidad liberarse de la dialéctica de opresión perpetuada.

La pedagogía crítica - llave de la libertad - es una tarea que le ha sido conferida únicamente a los oprimidos. Dentro del actual sistema injusto, oprimidos y opresores han perdido su humanidad; a pesar de ello, solo en el oprimido recae la fuerza necesaria para realizar la pedagogía de la liberación. Freire afirma que: "Ahí radica la gran tarea humanística e histórica de los oprimidos: liberarse a sí mismos y liberar a los opresores. Estos, que oprimen, explotan y violentan en razón de su poder, no pueden tener en dicho poder la fuerza de la liberación de los oprimidos ni de sí mismos. Solo el poder que renace de la debilidad de los oprimidos será lo suficientemente fuerte para liberar a ambos" (Freire 2017c: 41). Aquí yace uno de los rasgos éticos más patentes de la pedagogía del oprimido: entregarle al ser negado la dignidad del compromiso por su liberación. Esta idea permanece como anáfora en el libro, que incluso lleva como título su propia propuesta. Sin embargo, esta repetición parece solo ser el contrapunto con el cual Freire introduce la figura del maestro.

Dentro de una pedagogía del oprimido, donde él tenga que liberarse a sí mismo, ¿cuál es la pertinencia de un maestro que introduzca la pauta de la liberación? La entrada del maestro está apoyada en la tercera tesis de Feuerbach, a partir de la cual Freire afirma que: "ninguna realidad se transforma a sí misma"2 (Freire 2017c: 53). Se necesita una inserción crítica que provenga del exterior. Los oprimidos son presentados desde esta pedagogía como seres duales e inauténticos, pues al alojar al opresor en su conciencia han perdido su individualidad. Por eso el oprimido ignora su propia condición, circunstancia por la cual le resultaría imposible transformar su situación. La tarea del maestro es presentarle al oprimido su condición para que él pueda, ulteriormente, liberarse de ella.

2 Freire en la Pedagogía del oprimido hace un llamado a pie de página tras escribir la frase "ninguna realidad se transforma a sí misma" (Freire 2017c: 53). El propósito de su nota es citar textualmente la tercera tesis sobre Feuerbach: "La teoría materialista de que los hombres son producto de las circunstancias y la educación, y de que, por tanto, los hombres modificados son producto de circunstancias distintas y de una educación modificada, olvida que son los hombres, precisamente, los que hacen que cambien las circunstancias y que el propio educador necesita ser educado" (Marx, Engels 1973: 8). Freire, sin embargo, cita esta tesis para presentar solo la primera parte; y aquello que la teoría materialista había olvidado, permanece en el olvido. 
Habíamos acordado que la fuerza del opresor no puede liberar al oprimido. Ahora hay que considerar que el oprimido, por ser inauténtico, tampoco puede liberarse a sí mismo. Ante estas dos tesis aparentemente irresolubles aparece el maestro, como el gozne sobre el que girará el proyecto de Freire. Solo el maestro puede hacer posible la liberación del oprimido, pues él no es ni oprimido ni opresor. Inmediatamente resalta su naturaleza de figura aislada de toda relación de opresión. Este personaje robinsoniano encarna la responsabilidad hacia el otro, movido por lo que para él significa la justicia. El amor es su fuente inagotable, solamente un ser que ame al hombre podrá buscar su libertad: "Es imposible enseñar sin la capacidad forjada, inventada, bien cuidada de amar" (Freire 2017a: 26). Este amor incondicional le ha proporcionado al maestro el derecho a intervenir en la vida del otro en aras de buscar su libertad.

No podemos interceder en la vida de los otros llevándoles nuestra propia concepción de justicia. La responsabilidad hacia el otro debe fundamentarse desde la justicia de ese otro; en esto consiste el giro copernicano que supone la ética heterónoma. Intentaré trazar una lectura crítica con base en esta ética que inauguró Emmanuel Lévinas y que después de él muchos filósofos han nutrido.

El maestro es un filántropo tan privilegiado que tiene la oportunidad de ir repartiendo amor enseñando a los oprimidos su condición, con el propósito de liberarlos. Desde la ética heterónoma le tenemos que recordar al sujeto -en este caso el maestro- que su privilegio está fundado en la injusticia hacia el otro. No hay, como pretendía Freire, sujetos aislados de la contradicción de clases. El privilegio del maestro freiriano debe su existencia - en palabras de Walter Benjamin - a la "servidumbre anónima de sus contemporáneos" (Benjamin 2008: 42). Desde la ética heterónoma se ilumina el proceso por el cual este privilegio había permanecido oculto. Silvana Rabinovich nos explica cómo: "El otro insta al sujeto a reconocer su lugar 'propio' como usurpación y así impide que se instale en la comodidad ofrecida por una moral altruista" (Rabinovich 2018: 21). La ética heterónoma obliga al maestro a reconocer que él encubre una gran opresión.

Junto a este reclamo heterónomo aparece, en un ensayo intitulado From a Pedagogy for Liberation to Liberation from Pedagogy, una lectura de la figura del maestro en Freire. El maestro es, en efecto, un opresor. Pero su sistema lo ha encubierto, arrojándolo a reproducir la misma opresión contra la que él quería luchar. 
Freire's construction of mediators expresses a corruption of his awareness of oppression. His "conscience" operates as a veil, hiding from "liberated" agents of change their own oppression, the fact that their conscience is still embedded in an oppressive system and thus becomes counterproductive. Furthermore, it veils that such "conscience" adds oppression to the oppressed, disabling them while dismissing, denying, or disqualifying the fullness of their initiatives. This operation not only implies a specific, untenable arrogance-the hubris of possessing the true, universal conscience-it also serves the purpose of legitimizing the right of intervention in the lives of others (Esteva et al. 2005: 15). ${ }^{3}$

El maestro, creyéndose poseedor de la verdad, se ve obligado a actuar ante la tarea de la liberación del alumno. Esta conciencia que lo incita a actuar debe ser leída en clave colonial, pues le permite imponer aquello que él cree mejor para el otro. La hybris del maestro - tal y como lo mencionan Gustavo Esteva et al. en el fragmento que acabo de citar- da testimonio de un rasgo fundamental del educador educado en Freire. Él no solo se cree libre de opresión — sin serlo- , sino que privilegia su forma de ver el mundo sobre las demás. Tal y como sucedió con los frailes que querían salvar a los indios evangelizándolos. La alfabetización aparece, según estos pensadores, como un vino nuevo para botellas viejas: las botellas del colonialismo.

La desmesura del maestro freiriano no tiene comparación, él cree poder insertar en el alumno una visión del mundo hegemónica, mediada por el lenguaje escrito. Iván Illich nos habla de esta pretensión desmedida en La sociedad desescolarizada (2015). Illich no se posiciona en contra de Freire, más bien lo presenta como su amigo y alaba su labor pedagógica. A pesar de esto, en otros momentos critica ciertas cuestiones de la pedagogía en general que nos podrían recordar mucho las pretensiones de Freire. Illich, con la idea de privar de apoyo oficial a las escuelas y de desescolarizar la sociedad, impugna la idea de un maestro que nos libere de la opresión; contrariamente a Freire, los oprimidos se tienen que liberar a sí mismos de los maestros.

3 [La construcción de mediadores de Freire expresa una corrupción en su conciencia de la opresión. Su "conciencia" opera como un velo, ocultándole a los "liberados" agentes del cambio su propia opresión, el hecho de que su conciencia esté aún incrustada en un sistema opresivo, por tanto, lo vuelve contra productivo. Además, se oculta bajo el velo que esa "conciencia" añade opresión al oprimido, deshabilitándolos, desvalidándolos, negándolos o descalificando la amplitud de su iniciativa. Esta operación no solo implica una arrogancia específica e insostenible -la hybris de poseer la consciencia verdadera y universal - también sirve al propósito de legitimar el derecho de intervenir en la vida de otros.] (Traducción mía.) 
El aprendizaje no requiere enseñanza; confundir estos dos términos es una decisión política que encubre la falsa necesidad de una institución que no necesitamos: la escuela.

Illich es muy crítico; él sostiene que el maestro no puede liberarnos de ninguna opresión. Cree incluso que muchos de los que se autodenominan revolucionarios caen en el error de explotar al otro en aras de buscar su libertad. Debemos respetar la separación frente al otro, no someterlo a nuestra propia visión del mundo o de nuestro sentido de lo justo. La liberación que propone Freire, la frenética ambición de alfabetizar a cualquiera que no compartiera su forma de leer el mundo, se ve puesta en tela de juicio desde la lectura del filósofo austriaco: "La naturaleza totalmente destructiva y en constante progreso de la instrucción obligatoria cumplirá cabalmente su lógica final a menos que comencemos a liberarnos desde ahora de nuestra hybris pedagógica, nuestra creencia de que el hombre puede hacer lo que no puede Dios, a saber, manipular a otros para salvarlos" (Illich 2015: 237).

Uno de los lugares donde más fuertemente se ve encarnada hoy la propuesta de Freire es en las campañas de alfabetización. Para él, el analfabetismo representaba uno de los peores males de la humanidad. El analfabetismo se dedica, asegura Freire, a "castrar el cuerpo consciente y hablante de mujeres y de hombres prohibiéndoles leer y escribir" (Freire 2017a: 24). Freire piensa que la única forma de leer el mundo es mediante la lectoescritura, por eso el analfabeto está, según él, negado en este mundo. Por ello, los maestros alfabetizadores le entregarán al alumno la posibilidad de leer su mundo mediante el lenguaje escrito. Estos maestros son presentados como mediadores con plena conciencia de que son parte de un mundo plagado de injusticia. El alumno, en cambio, ignora su relación con este mundo y genera una imagen desorganizada de él. El maestro en Freire ayuda al alumno a organizar su visión del mundo: "Para el educador-educando, dialógico, problematizador, el contendido programático de la educación no es una donación o una imposición [...] sino la devolución organizada sistematizada y acrecentada al pueblo de aquellos elementos que este le entregó en forma inestructurada" (Freire 2017c: 113). El maestro le entrega al alumno una visión nueva del mundo.

La hybris pedagógica que sirvió para caracterizar al maestro freiriano, y que elaboramos en los dos textos arriba citados (Illich y Esteva), puede ser retomada mediante el concepto de razón metonímica expresada por el sociólogo portugués Boaventura de Sousa. La razón metonímica "se reivindica como la única forma de racionalidad y, por consiguiente, no se dedica a descubrir 
otros tipos de racionalidad o, si lo hace, es solo para convertirlas en materia prima" (De Sousa 2015: 101). Cuando Freire afirma que el analfabetismo violenta a las personas, coloca a la comprensión occidental y letrada del mundo como la única posible. Alfabetizar es homogeneizar los saberes, pues ninguno puede escapar a aquel que indica la razón dominante. Es decir, la razón detrás de la Pedagogía del oprimido es la razón metonímica. Freire no acepta otras formas de transmisión del saber, como podría ser la oral; él insiste en la lectoescritura como único camino para la liberación.

Todo el desperdicio de experiencia que supone el encerrar la diversidad del mundo en una sola razón, es nombrado por De Sousa como "epistemicidio". $\mathrm{Al}$ fundar una única forma de saber que totalice el conocimiento, estamos diezmando prácticas y experiencias por las cuales los individuos solían comunicar sus saberes dentro de las comunidades. El proyecto de alfabetización de Freire conlleva un proyecto de epistemicidio. En su artículo Experiencia y pobreza, de 1933, Walter Benjamin lo describía así, siguiendo la idea de que hemos cambiado experiencia por progreso: "Nos hemos vuelto pobres. Hemos ido perdiendo uno tras otro, pedazos de la herencia de la humanidad; a menudo hemos tenido que empeñarlos en la casa de préstamos por la centésima parte de su valor, a cambio de la calderilla de lo 'actual'" (Benjamin 2010: 221-222). Freire está dispuesto a arriesgar toda la tradición oral, u otras formas de transmisión del saber, en aras de un progreso galvanizado por las campañas de alfabetización. A diferencia de Benjamin, Freire antepone el progreso a la experiencia y no tiene reparo en aceptar que, cuando se refiere a la posibilidad de un cambio contenido en la vieja sociedad "es preciso que los viejos agoten sus vigencias cediendo lugar a los nuevos” (Freire 2017b: 40-41). Hay una noción de progreso que permea todo el proyecto de alfabetización y que arrastrará al maestro irremediablemente hacia el futuro. ${ }^{4}$ La determinación de Freire de buscar nuevas soluciones a problemas viejos le permite esquivar un conservadurismo a expensas de caer dentro de tal noción de progreso. El problema que encontró Benjamin fue retomado por Boaventura de Sousa en Una epistemología del sur. El sociólogo explica que Benjamin halló

4 Hago la comparación entre el proyecto de alfabetización y el huracán que se arremolina en las alas del ángel de la historia descrito por W. Benjamin en su IX tesis sobre la historia. En esta, Benjamin presenta al progreso como aquello que nos impide "recomponer lo destruido" (Benjamin 2008: 44), pues nos lleva irremediablemente hacia el futuro. Freire parece soplar ese huracán al desarrollar sus campañas de alfabetización: yendo ciegamente hacia "mejor" y dejando al olvido todas las ruinas que crecen hasta el cielo. 
el problema, pero no la causa: la razón metonímica que conlleva al enorme desperdicio de experiencias está fundada en la arrogancia de quien en ella está inscrito.

El problema de la hybris pedagógica encuentra su fundamento en la razón metonímica. El maestro embriagado en esta razón no reconoce en el alumno a un otro que en su alteridad tiene diferentes experiencias y una diferente concepción de justicia. El maestro franquea la línea que indica la alteridad del alumno e imprime en este su saber. No solo negando el saber anterior del alumno sino presuponiendo, mediante la explicación, que este no tiene la capacidad de adquirirlo por cuenta propia. Jacques Rancière, para distinguir al maestro inscrito en esta pedagogía clásica de El maestro ignorante, afirma que: "Explicar algo a alguien es, en primer lugar, demostrarle que no puede comprenderlo por sí mismo" (Rancière 2007: 21). Mediante la crítica a esta razón metonímica en la pedagogía crítica de Freire, podríamos buscar recuperar toda la experiencia perdida y afirmar la alteridad del alumno. Sigo la propuesta de De Sousa problematizándola desde el campo de la ética heterónoma. Ante las campañas de alfabetización de Freire y la pedagogía del oprimido, aparece la traducción como un nuevo panorama para la pedagogía.

La sociología de las ausencias y la sociología de las emergencias propuestas por Boaventura de Sousa anuncian, dentro de sus cinco ecologías, la ecología de saberes. En el fondo de esta propuesta se suscribe la cuestión de cómo adquirir nuevos saberes, sin desplazar al olvido los viejos. Este es el punto neurálgico de lo que llaman la utopía del interconocimiento: "aprender nuevos y extraños saberes sin necesariamente tener que omitir los anteriores y propios" (De Sousa 2015: 114). Frente al constante desperdicio de experiencias llega el trabajo de traducción. Aquí el terreno poético de la traducción se vuelve el terreno político de la resistencia. "El trabajo de traducción crea las condiciones para emancipaciones sociales concretas de grupos sociales concretos en un presente cuya injusticia es legitimada con base en un masivo desperdicio de la experiencia" (De Sousa 2015: 151). A partir de la tarea de la traducción podemos escapar de todos los saberes hegemónicos que totalizan el mundo y generar un espacio que exceda la totalidad dando cuenta de la inagotable riqueza de saberes en el mundo.

Boaventura de Sousa nos muestra cómo el trabajo de traducción puede funcionar como resistencia. La presenta como un trabajo que articula y le da sentido a toda la diversidad de saberes en el mundo, sin someterlos a una teoría general. Es un trabajo de imaginación epistemológica y de justicia cog- 
nitiva que se nos presenta como "la teoría general de la imposibilidad de una teoría general" (De Sousa 2015: 144). La tarea del traductor es la de buscar justicia en un mundo carente de ella, construyendo nuevos espacios para la emancipación social basándose en la diversidad de experiencias sociales que nacen de saberes antes ignorados.

La educación como práctica para la libertad queda desplazada; el maestro freiriano - estandarte de la hegemonía letrada - ya no tiene fuero dentro del terreno de la traducción. "La verdad se vincula, de este modo, a la relación social, que es justicia. La justicia consiste en reconocer en el otro a mi maestro" (Lévinas 2016: 74). De este (otro) modo, Lévinas nos ofrece la ética como posibilidad de exceder al mundo que había sido totalizado por la moral vigente. El sujeto ya no es el maestro inserto en la razón metonímica, ahora es sujeto 5 a otro. El maestro freiriano ha devenido maestro levinasiano.

En consonancia con el sociólogo portugués aparece un concepto de traducción que, desde la ética heterónoma, se encarna en un sujeto que se responsabiliza por el otro asumiéndose heredero y encomendándose al legado de su palabra. Silvana Rabinovich concibe desde la traducción el acto ético de la hospitalidad y la resistencia. Su pensamiento — que sondea y radicaliza la ética levinasiana - traza un horizonte de justicia desde donde podemos proponer alternativas al problema de la emancipación vernácula. Nos ofrece un concepto de traducción dialogando desde la ética hasta la política, el cual utilizaremos para abrir un panorama ético en la pedagogía. Pensemos, pues, al traductor como alternativa al maestro freiriano: "El traductor encarna a la subjetividad heterónoma levinasiana, vulnerable — nada viril—, inmerso en una lengua que le es heredada; tiene la misión de transmitir al porvenir esa palabra proveniente de antaño, de una otredad inasimilable" (Rabinovich 2012: 145). Recorreremos el camino que marca la traducción como justicia.

Este concepto de traducción nos propone otra forma de leer el mundo: más allá de la esencia. Por eso nos puede proporcionar alternativas para la pedagogía de la liberación. Si Freire repudia el analfabetismo es porque encuentra en la escritura algo que la oralidad no permite. Cuando describe la sociedad que él quiere cambiar hace hincapié en sus "alarmantes índices de analfabetismo,

5 "La subjetividad levinasiana no se define por la voluntad [...] sino por la sujeción al prójimo, anterior a cualquier acto voluntario" (Rabinovich 2018: 18) de esta forma la noción de sujeto en la ética levinasiana abandona la preponderancia de su cualidad moderna de "Yo" y se convierte en la primera persona del indicativo: estar sujeto a otro. 
aún hoy persistentes" (Freire 2017b: 41). Quiere abrir a la sociedad mediante el diálogo liberador y dotarla de la palabra escrita. La lectoescritura no solo permite la lectura de un texto, abre el mundo en el que el ser humano vive. En Cartas a quien pretende enseñar confiesa que los analfabetos: "inmersos en la realidad de su pequeño mundo, no eran capaces de ver" (Freire 2017a: 52). Por otra parte, Ivan Illich describe bien el papel preponderante que tiene la alfabetización dentro de la búsqueda por la libertad:

Por la tarde, los aldeanos se reúnen para conversar sobre esas palabras clave. Comienzan a percatarse de que cada palabra permanece en el pizarrón incluso después de haberse desvanecido su sonido. Las letras continúan abriendo, como llaves, la realidad y haciéndola manejable como problema. Frecuentemente he presenciado cómo en unos participantes crece la conciencia social y cómo se ven impelidos a actuar políticamente con la misma velocidad con que aprenden a leer. Parecen tomar la realidad en sus manos conforme la escriben (Illich 2015: 207).

El inagotable carácter crítico de Illich supo mirar con buenos ojos el proyecto de su amigo. Sin embargo, en la cita anterior podemos ver una primacía voraz por parte de la palabra escrita, como si la oralidad no estuviera dotada de la fuerza suficiente para cambiar el mundo. La ética heterónoma se sitúa del otro lado: sin negar la palabra escrita, dota a la palabra oral con la fuerza de su actualidad. Desde Totalidad e infinito Lévinas responde a esta cuestión poniendo el acento en la palabra hablada — proferida—, pues ella es la que interpela al otro. "La actualidad única de la palabra la arranca a la situación en la que comparece y que da la impresión de prolongar. Aporta eso de lo que la palabra escrita ya está privada: la condición de maestra" (Lévinas 2016: 71). La palabra proferida no niega a la escrita, solo se inserta en el presente actualizándola, es decir: radicalizándola en el plano ético. Si bien la palabra que se lee en voz alta actualiza la escritura (como en la cita de Lévinas), la palabra hablada - y especialmente escuchada - siempre es anterior a cualquier escritura. "En la heteronomía levinasiana, el lenguaje — siempre hablado- nos acoge en su seno; nuestros oídos se dejan enseñar y solo más tarde hablamos" (Rabinovich 2018: 19). ¿Por qué despojar al lenguaje oral de su lugar? Solo para justificar la entrada de la palabra escrita: amiga de la historia y el progreso.

La lengua es una herencia que, a la vez, tenemos la responsabilidad de heredar. Sin embargo, esta responsabilidad no debe confundirse con el ahínco 
de imponerla a aquellos a los que les corresponde otro legado. Desde la ética heterónoma es imposible justificar el derecho a intervenir en la vida del otro. Dentro de una comunidad, la custodia de la lengua y la experiencia se cuida para ser transmitida de generación en generación. Aquí la palabra del otro se privilegia siempre sobre sí misma. Pero para la comunidad la resistencia se da presentándose como autonomía al exterior. La heteronomía no se contrapone a la autonomía; más bien se afirma como la madre de esta. "Mientras en el orden interno - donde prevalece la escucha - se rige por una heteronomía radical, hacia el Estado nacional - que intenta minimizar o borrar las diferencias étnicas a fin de fortalecer el común denominador- se comporta como 'autonomía'” (Rabinovich 2018: 30-31). Es aquí donde la traducción se convierte en resistencia ante imposiciones extranjeras. La traducción —diálogo heterónomo- le permite a la víctima que ha sufrido el despojo de su palabra revelarse ante el sujeto exigiendo justicia. La ética abre el horizonte para que se haga justicia del otro, de aquel cuya justicia ha sido negada. Por otra parte, el miembro de una comunidad que sufre de una imposición violenta no tiene por qué acoger la justicia del opresor.

La relación con el otro se genera desde la ética heterónoma como hospitalidad. A diferencia del proyecto alfabetizador que era profundamente hostil —negando la alteridad del otro mediante un diálogo colectivo—, la ética genera una proximidad que afirma la alteridad de otro. El carácter ético de la proximidad levinasiana radica en el arte de la separación. La filosofía de Lévinas - crítica a la totalidad - nace de un pensamiento fuera del ser — ensayo sobre la exterioridad-. Para que el otro mantenga su otredad tiene que estar radicalmente fuera de mí, separado por la distancia que indica la trascendencia. Como afirma el filósofo: "El poder del Yo no franqueará la distancia que indica la alteridad del Otro" (Lévinas 2016: 33). Si el maestro franquea la distancia, entonces violenta y destruye la alteridad del alumno. La proximidad del traductor se da con la cercanía de la separación. En lugar de totalizarlo desde nuestro lenguaje y nuestra concepción de justicia, nos mantenemos separados a través de la idea de infinito. El otro, para que sea otro, tiene que ser radicalmente exterior. Asumir la justicia y la palabra del otro, desde la perspectiva de Lévinas, es asumir lo absolutamente exterior.

La ética es dejar que el otro viva como otro. No siendo cómplices de su injusticia sino estando sujetos a lo que ese otro entiende como justo. Freire creía que su concepción de justicia debía ser donada al oprimido. Pero el pedagogo negó en ese momento la posibilidad de que el otro efectuara su propia 
justicia. Estaba movido por una moral que lo avalaba para ser injusto. La ética es permitir que el otro se me presente desde su exterioridad (a lo que Lévinas llamó epifanía del rostro ${ }^{6}$ ) y yo acogerlo con una hospitalidad cabal. Esta hospitalidad consiste, en todo caso, en anteponer la justicia del otro a la propia. Por eso, la heteronomía no es el acto altruista de ayudar al otro (justicia para el otro), sino el acto ético de acogerlo sin imponerle condiciones y responsabilizarnos por él (justicia del otro).

El traductor cumple de forma completa la exigencia ética. A él se le presenta el otro exclamando la palabra que - desde la traducción heterónoma- le va a ser inapropiable. Sin restarle alteridad, produce una proximidad con el otro. Pues la palabra traducida nunca elimina la palabra del otro: se exclama aparte, no se imprime sobre ella. Porque la traducción, según Walter Benjamin: "mira desde afuera, mejor dicho, desde enfrente y sin penetrar en ella hace entrar al original en cada uno de los lugares en que eventualmente el eco puede dar, en el propio idioma, el reflejo de una obra escrita en una lengua extranjera" (Benjamin 2012: 129-130). Esta noción de traducción es radicalizada tanto en la sociología de las ausencias y la sociología de las emergencias como en la ética heterónoma. El traductor puede dar cuenta de un mundo que excede su comprensión y ofrecer asilo para el lenguaje y la forma de su transmisión. "La relación de Mismo y Otro (o metafísica) se pone en juego originalmente como discurso en que Mismo, recogido en su ipseidad de «yo» (de ente particular y autóctono), sale de sí" (Lévinas 2016:34). El otro perturba la comodidad en la que el traductor, antaño, se había apoltronado.

Leer a Freire en clave heterónoma nos entregaría una pedagogía de la otredad. Habíamos empezado el presente artículo presentando a la pedagogía como un saber que asume la tarea de enseñarle a otro. Sin embargo, hemos visto cómo esa responsabilidad justificó el derecho para intervenir en la vida y en el conocimiento de ese otro. A diferencia de esta, la responsabilidad que se da desde la traducción adquiere la noción extranjera de justicia. Asume la justicia del otro y la privilegia sobre la propia. Es hospitalidad pues abre la casa para la visita de la palabra y la justicia ajena. La traducción nos permite pensar que tanto nuestra justicia como nuestra palabra nunca son propias; la justicia heterónoma nos recuerda nuestro carácter de herederos y custodios de la lengua y la justicia. La traducción —más que pasar un texto de un idioma

6 El rostro ha sido trabajado en diversos lugares dentro de la obra de Lévinas (Lévinas 2016: 221). 
a otro- se da desde el momento en el que aprendemos la palabra extranjera de nuestra madre o cuando aguzamos el oído para dejarnos interpelar por la palabra del otro. Pero, sobre todo, la traducción se da cuando escuchamos el reclamo de injusticia y respondemos buscando aquella justicia negada.

Para generar una pedagogía de la otredad tenemos que partir de un trabajo constante de traducción. Por eso, resulta urgente y necesario que, dentro de cualquier aula, ante cualquier maestro, durante cualquier campaña de alfabetización, la ética heterónoma irrumpa en la espontaneidad de aquel que quiera enseñar y le recuerde la infinita responsabilidad que tenemos por el otro. Así, la traducción germinará como otro panorama para la pedagogía.

\section{Bibliografía}

Benjamin, Walter (2008). Tesis sobre la historia y otros fragmentos, trad. Bolívar Echeverría. México, Itaca.

Benjamin, Walter (2010). “Experiencia y pobreza”, Obras, libro II, vol. 1, trad. Jorge Navarro Pérez. Madrid, Abada: 216-222.

Benjamin, Walter (2012). "La tarea del traductor", Ensayos escogidos, trad. Héctor A. Murena. México, Ediciones Coyoacán: 119-137.

De SousA, Boaventura (2015). Una epistemología del sur, ed. José Guadalupe Gandarilla Salgado. México, Siglo XXI.

Esteva, Gustavo, Dana L. Stuchul y Madhu Suri Prakash (2005). "From a pedagogy for liberation to liberation from pedagogy”, en Chet Bowers (ed.), Rethinking Freire. New Jersey, Lawrence Erlbaum Associates: 13-30.

Freire, Paulo (2017a). Cartas a quien pretende enseñar, trad. Stella Mastrángelo. México, Siglo XXI.

Freire, Paulo (2017b). La educación como práctica de la libertad, trad. Lilién Ronzoni. México, Siglo XXI.

Freire, Paulo (2017c). Pedagogía del oprimido, trad. Jorge Mellado. México, Siglo XXI. ILliCH, Iván (2015). "La sociedad desescolarizada", Obras reunidas I, trad. Gerardo Espinoza y Javier Sicilia. México, Fondo de Cultura Económica: 189-323.

LÉvinas, Emmanuel (2016). Totalidad e infinito, trad. Miguel García-Baró. Salamanca, Sígueme.

MarX, Carlos, y Federico Engels (1973). “Tesis sobre Feuerbach”, Obras escogidas en tres tomos, tomo I. Moscú, Progreso: 7-10.

Rabinovich, Silvana (2012). "Heteronomía y traducción (o cuando traducir es padecer las cuatro locuras platónicas)", en Adriana de Teresa (coord.), Tránsitos y umbrales en los estudios literarios. México, Universidad Nacional Autónoma de México: 143-156.

RABinOVICH, Silvana (2018). Interpretaciones de la heteronomía. México, Universidad Nacional Autónoma de México. 
RANCiÈRE, Jacques (2007). El maestro ignorante, trad. Claudia Fagaburu. Buenos Aires, Libros del Zorzal.

\section{Juan Heiblum Amaya}

Estudiante de Filosofía en la Facultad de Filosofía y Letras de la UnAM. Durante 2017-2018 participó en el proyecto PAPIIT IN 402317 "Heteronomías de la justicia: nomadismo y hospitalidad en el lenguaje". Actualmente participa en el proyecto PAPIIT IN 401119 "Heteronomías de la justicia: territorialidades nómadas". Realizó la entrada de "Islam saharaui” para el Glosario nómada, publicado en la página web: <http://www.iifl.unam.mx/justiciadelotro/seccs. php?idSec=6\&pos=6>, y un capítulo homónimo en el libro Palabras nómadas en camino a una justicia del otro (2020). 